\title{
PEMOLESAN TUMPATAN KOMPOSIT DAPAT MENURUNKAN ANGKA PERUBAHAN WARNA (DISKOLORISASI) PADA RESIN KOMPOSIT NANOFILLER YANG DISEBABKAN OLEH PENGGUNAAN OBAT KUMUR CHLORHEXIDINE
}

\author{
I Gusti Ketut Armiati \\ Bagian Konservasi Gigi, Fakultas Kedokteran Gigi, Universitas Mahasaraswati Denpasar \\ email: armiatigstkt@yahoo.co.id
}

\begin{abstract}
Nanofiller composite resin restoration has a major problem, namely color changes. Polishing are factors that determine color change and if added to using mouthwash for a long time can cause more significant color changes. The $0.2 \%$ chlorhexidine gluconate mouthwash is a mouthwash that is often used in the community because it has low toxicity. However, using the chlorhexidine gluconate $0.2 \%$ mouthwash in the long term can cause discoloration in the composite resin. The purpose of this study was to determine the difference between discoloration of polished and unpolished nanofiller composite resin on the soaking of $0.2 \%$ chlorhexidine gluconate mouthwash. The method used in this study is purely experimental research with a pretest and post test with control group design, using 24 samples of premolar teeth prepared with class II cavity design and then filled with nanofiller composite resin. The samples were then divided into 4 treatment groups, namely polished, non-polished nanofiller composite resin, $0.2 \%$ chlorhexidine gluconate mouthwash and distilled water. Soaking was carried out 24 hours a day for 5 days in an incubator at $37^{\circ} \mathrm{C}$. Changes in the color of each group were measured using Shade Guide Vita Classical. The hypothesis testing of this research was carried out by descriptive analysis which was then tested by the Shapiro-Wilk test for its normality test and Leven's test to test its homogeneity with a significance value of 0.05. Mann-Whitney test for different tests. Based on the results of this study, it was found that the discoloration of the polished nanofiller composite resin was smaller than that which was not polished on the soaking of chlorhexidine mouthwash $0.2 \%$
\end{abstract}

Keywords: Nanofiller Composite Resin, Color Change, Polishing, Chlorhexidine Gluconate Gargle 0.2\%.

\section{PENDAHULUAN}

Keindahan dan kecantikan merupakan hal yang diperhatikan oleh masyarakat di era modern ini. Penampilan menarik merupakan keharusan bagi sebagian manusia. Keindahan yang dirasakan oleh setiap individu berbeda-beda, karena itu keindahan bersifat subyektif dalam arti sukar ditentukan batasbatasnya. Hal tersebut merupakan kewajiban bagi dokter gigi untuk memahami maksud dan keinginan dari pasien mengenai hal yang ideal bagi dirinya.

Sejalan dengan berkembangnya dunia kedokteran gigi dan teknologi penunjangnya saat ini, maka Estetik Dentistry gigi semakin berkembang dalam mengantisipasi kebutuhan masyarakat terhadap perbaikan penampilan. Kemajuan ilmu pengetahuan secara umum juga sangat berpengaruh pada kebutuhan masyarakat akan perawatan gigi, yang awalnya hanya untuk menghilangkan rasa sakit dan pemenuhan fungsi pengunyahan, maka saat ini kecenderungan akan perawatan gigi lebih menitikberatkan kepada masalah estetik. ${ }^{11}$ Perubahan warna gigi (diskolorisasi) dapat menjadi problem estetika, terutama pada gigi anterior yang jelas terlihat saat seseorang berinteraksi dengan orang lain, yaitu saat berbicara atau tersenyum dan dapat memberikan dampak psikologis pada diri seseorang. Oleh karena itu, seseorang akan melakukan perawatan terhadap perubahan giginya untuk memperbaiki masalah estetiknya tersebut. ${ }^{9}$

Menurut Grossman, perubahan warna gigi dapat diklasifikasikan menjadi warna ekstrinsik dan intrinsic. ${ }^{3}$ Perubahan warna intrinsik adalah pewarnaan gigi oleh noda yang terdapat di dalam email dan dentin selama odontogenesis atau setelah erupsi gigi. Perubahan warna gigi secara intrinsik dapat disebabkan oleh penyebab sistemik, metabolisme, genetika serta faktor lokal. Sedangkan penyebab perubahan warna ekstrinsik adalah chromogens berasal dari asupan sumber diet, seperti kopi, teh, wortel, coklat, atau dari tembakau, larutan kumur, atau plak pada permukaan gigi. $^{2}$

Perubahan warna ekstrinsik dapat dihilangkan dengan cara scaling. Pada gigi yang mengalami perubahan warna intrinsik atau perubahan warna ekstrinsik yang sulit dihilangkan dengan scaling, dapat diperbaiki dengan bleaching atau pemutihan gigi. ${ }^{2}$ Tujuan dental bleaching adalah untuk mengembalikan fungsi estetis. ${ }^{4}$ Selain dengan scaling dan bleaching, dapat diperbaiki dengan melakukan restorasi pada gigi. mengandung bahan pewarna, kebersihan mulut yang buruk dan penggunaan obat kumur.

Bahan tumpatan atau restorasi gigi digunakan untuk memperbaiki gigi secara biologis, fungsional dan estetik. Bahan restorasi gigi harus aman digunakan 
dalam lingkungan mulut dan memiliki kesamaan warna dengan gigi asli untuk alasan kesehatan dan estetik. ${ }^{10}$ Menurut Jurreta Sintawati dkk (2008) resin komposit merupakan bahan restorasi gigi yang banyak digunakan dewasa ini untuk menggantikan struktur gigi yang hilang serta memodifikasi warna dan kontur gigi dengan tujuan estetik. Penggunaan resin komposit sebagai bahan restorasi di bidang kedokteran gigi semakin meningkat dan dipengaruhi oleh beberapa faktor, antara lain usaha keinginan pasien agar gigi kembali utuh, dapat berfungsi dengan baik dan hasilnya terlihat seperti gigi asli. ${ }^{8}$ Keunggulan lainnya dari resin komposit adalah banyak digunakan pada restorasi gigi permanen karena preparasi kavitas tidak mengurangi banyak jaringan gigi yang sehat. Beberapa evaluasi yang telah dilakukan pada bahan tumpatan resin komposit menyatakan bahwa didapatkan adanya kekurangan pada bahan tumpatan resin komposit yaitu berupa perubahan fisik yang terjadi pada bahan tersebut. Salah satu diantaranya adalah perubahan warna. ${ }^{1}$ Resin komposit terdiri dari empat komponen utama, yakni matriks polimer organik, partikel filler innorganik, coupling agent dan sistem inisiator-akselator. ${ }^{8}$ Resin komposit dapat diklasifikasikan berdasarkan karakteristik dari pengisiannya, yaitu : makrofiller, mikrofiller, hybrid, microhybrid dan nanofiller.

Resin komposit nanofiller saat ini sering digunakan. Nanofiller telah dikembangkan dengan tujuan menggabungkan kelebihan dari resin komposit hybrid dan mikrofiller dalam bahan restorasi yang sama. Resin komposit nanofiller memiliki ukuran filler yang sangat kecil sehingga resin komposit nanofiller memiliki kelebihan permukaan yang halus dan mengkilat, pengkerutan polimerisasi yang lebih minim dan resistensi yang lebih baik serta memiliki daya atrisi yang rendah sehingga resin komposit nanofiller banyak digunakan saat ini bahkan untuk gigi posterior. Ukuran partikel filler sebesar $0,005-0,01 \mu \mathrm{m} .{ }^{10}$

Partikel pengisi pada resin komposit nanofiller memiliki kombinasi yang unik antara nanopartikel individual dan nanocluster yang akan mengurangi jumlah ruang interstisial antara partikel bahan pengisi sehingga dapat meningkatkan sifat fisik dan hasil poles yang lebih baik bila dibandingkan dengan resin komposit lain. ${ }^{10}$ Menurut Santos dkk (2003) dan Omata dkk (2006) mengemukakan bahwa stabilitas warna pada tumpatan adalah sifat yang bergantung pada faktor seperti polimerisasi dari material dan kebiasaan pasien dalam mengkonsumsi makanan yang

Penggunaan obat kumur semakin berkembang baik di dunia kedokteran gigi ataupun masyarakat. Obat kumur merupakan suatu larutan atau cairan yang digunakan untuk membantu memberikan kesegaran pada rongga mulut serta membersihkan mulut dari plak dan organisme yang menyebabkan penyakit dirongga mulut. Berkumur dengan obat kumur dapat menghilangkan bakteri di sela-sela gigi yang tidak terjangkau oleh sikat gigi. Komposisi dalam obat kumur pada prinsipnya terdiri dari zat aktif, pelarut, surfaktan dan pemberi rasa. Pelarut dalam obat kumur umumnya mengandung air dan alkohol. Alkohol yang biasanya digunakan adalah etanol yang kadarnya bervariasi antara $0 \%$ sampai $27 \%$.

Chlorhexidine merupakan antibakteri dengan spektrum luas, toksisitasnya rendah, dan larut dalam air. Chlorhexidine telah terbukti efektif terhadap bakteri rongga mulut karena dapat mengurangi mikroorganisme plak. ${ }^{7}$ Penggunaan obat chlorhexidine dalam jangka panjang tidak dianjurkan karena efek samping yang dapat terjadi adalah gangguan pengecapan, sensasi rasa terbakar, perubahan warna gigi, restorasi, dan membran mukosa, serta peningkatan pembentukan kalkulus. ${ }^{6}$

\section{BAHAN DAN METODE}

Metode yang digunakan dalam penelitian ini adalah metode eksperimental murni dengan pretest and posttest with control group design, yaitu penelitian untuk mengetahui perubahan warna komposit nanofiller yang dipoles dan tidak dipoles pada perendaman larutan obat kumur chlorhexidine. Sampel pada penelitian ini menggunakan gigi premolar satu rahang bawah manusia.

Sampel untuk 4 kelompok masing-masing berjumlah 6 buah gigi, jadi total sampel ada 24 buah gigi. Penelitian ini dilakukan di Laboratorium Mikrobiologi Fakultas Kedokteran Universitas Udayana dengan prosedur sebagai berikut membuat outline form design restorasi kelas dua pada gigi premolar satu rahang bawah, kemudian melakukan preparasi pada 24 sampel dengan menggunakan mikromotor dan round diamond bur. Sebelumnya semua gigi dilapisi dengan kalsium hidroksida pada kavitasnya dengan tujuan untuk mencegah asam yang berasal dari etsa atau resin akan menyebabkan iritasi pada pulpa, selanjutnya permukaan dibersihkan dengan air selama 25 detik dan dikeringkan menggunakan airway syringe.

Dilanjutkan dengan prosedur pengetsaan selama 20 detik lalu dibilas air dan dikeringkan menggunakan airway syringe. Selanjutnya, mengaplikasikan bahan bonding kedalam kavitas dan dioleskan selapis tipis dan dikeringkan menggunakan light cured selama kurang lebih 25 detik. Instrumen plastic filling digunakan untuk mengaplikasikan komposit sehingga komposit masuk ke dalam kavitas secara merata dan juga untuk membentuk sesuai dengan anatomi gigi. Teknik aplikasi komposit adalah layer by layer. Ujung sinar harus diletakan sedekat mungkin dengan permukaan resin dan lam penyinaran selama 20 detik.

Selanjutnya sampel diberi perlakuan dengan membagi menjadi 4 kelompok masing-masing 6 sampel untuk kelompok yang dipoles, tidak dipoles, pada perendaman obat kumur chlorhexidine dan aquadest. Untuk kelompok yang dipoles menggunakan silicon rubber atau rubber cup. Perendaman sampel dilakukan di Laboratorium Mikrobiologi Fakultas Kedokteran Universitas Udayana. Sampel direndam pada larutan saline terlebih dahulu selama 24 jam dengan suhu $37^{\circ} \mathrm{C}$ dalam inkubator agar dapat terjadi polimerisasi penuh, 
dan selanjutnya dilakukan pengukuran awal dengan menggunakan alat ukur Shade Guide Vita Classical.

Setiap sampel direndam pada larutan obat kumur chlorhexidine dan aquadest. Sampel direndam pada larutan obat kumur chlorhexidine dan aquadest dimasukan kedalam inkubator dengan suhu $37^{\circ} \mathrm{C}$ selama 5 hari dan larutan diganti setiap 24 jam. Sampel yang direndam sesuai waktunya diambil satu persatu dari wadah menggunakan pinset dan diletakan dalam nierbeken dan diukur kembali dengan menggunakan shade guide vita classical.

Uji normalitas menggunakan Shapiro-Wilk test dan uji homogenitas dengan menggunakan Levene's test serta uji pengaruh perlakuan kelompok menggunakan Wilcoxon test dan uji perbedaan dengan menggunakan Mann-Whitney.

\section{HASIL DAN PEMBAHASAN}

Hasil penelitian perbedaan perubahan warna restorasi resin komposit nanofiller yang dipoles dan tidak dipoles pada perendaman obat kumur chlorhexidine gluconate $0,2 \%$.

Tabel 1. Hasil Uji Normalitas Data Perubahan Warna

\begin{tabular}{lccc}
\multirow{2}{*}{ Kelompok } & \multicolumn{3}{c}{ Shapiro Wik } \\
\cline { 2 - 4 } & $N$ & Statistic & Sig. \\
\hline $\begin{array}{l}\text { Aquadest } \\
\text { Larutan } \\
\begin{array}{l}\text { Chlorhexidine } \\
0.2 \%\end{array}\end{array}$ & 9 & & \\
\hline
\end{tabular}

Hasil uji normalitas data penelitian pada Tabel 1. pada semua kelompok pre dan post aquades tidak menunjukkan hasil karena merupakan data yang konstan, sedangkan pada kelompok post larutan chlorhexidine $0.2 \%$ lebih kecil dari 0,05, sehingga data yang digunakan merupakan data yang tidak berdistribusi normal. Maka penelitian ini di uji dengan menggunakan uji statistik non parametrik.

Tabel 2. Perbedaan rerata kelompo sampel yang dipoles dan tidak dipoles

\begin{tabular}{|l|r|r|r|r|}
\hline \multicolumn{1}{|c|}{ Ranks } \\
\hline Hasil & Kelompok & N & $\begin{array}{r}\text { Mean } \\
\text { Rank }\end{array}$ & Sum of Ranks \\
& Dipoles & 6 & 4.25 & 25.50 \\
& Tidak & 6 & 8.75 & 52.50 \\
& dipoles & & & \\
& Total & 12 & & \\
\hline
\end{tabular}

Berdasarkan Tabel di atas terlihat bahwa restorasi resin komposit yang dipoles didapatkan ratarata diskolorisasi 4.25 sedangkan pada perlakuan kelompok 2 yaitu 6 sampel untuk restorasi resin komposit yang tidak dipoles didapatkan rata-rata diskolorisasi 8.75. Hal ini menunjukkan bahwa skor diskolorisasi pada restorasi resin komposit nanofiller yang dipoles lebih kecil daripada restorasi resin komposit nanofiller yang tidak dipoles pada perendaman dengan menggunakan obat kumur chlorhexidine gluconate $0.2 \%$.

Tabel 3. Uji Perbedaan dengan Mann-Whitney Test

Test Statistics $^{a}$

\begin{tabular}{|c|c|}
\hline & Hasil \\
\hline Mann-Whitney U & 4.500 \\
Wilcoxon W & 25.500 \\
Z & -2.303 \\
\hline Asymp. Sig. (2-tailed) & .021 \\
Exact Sig. [2*(1-tailed Sig.)] & $.026^{\mathrm{b}}$ \\
\hline
\end{tabular}

Berdasarkan Tabel 3 diatas diperoleh nilai $\mathrm{Z}$ sebesar -2.303 dengan nilai signifikansi 0.021 lebih kecil dari 0,05. Hasil ini membuktikan bahwa terdapat perbedaan diskolorisasi (perubahan warna) yang signifikan antara resin komposit nanofiller yang dipoles dan tidak dipoles pada gigi premolar sebelum dan sesudah dilakukan perendaman pada larutan obat kumur chlorhexidine $0,2 \%$ dengan temperature $37^{\circ} \mathrm{C}$.

Resin komposit yang tidak dipoles memiliki perubahan warna yang jauh lebih tinggi disebabkan karena tekstur permukaan bahan restorasi memiliki pengaruh yang besar pada perubahan warna dan tampilan estetik pada restorasi langsung dan tidak langsung. Selain itu, zat yang terkandung dalam obat kumur chlorhexidine gluconate 0,2\% lebih mudah melekat pada permukaan restorasi yang kasar. Semakin kasar permukaan restorasi maka diskolorisasi akan terjadi semakin banyak.

Berbeda dengan restorasi resin komposit yang dipoles, restorasi resin komposit nanofiller yang dipoles lebih sedikit mengalami perubahan warna. Hal ini dikarenakan restorasi resin komposit nanofiller yang dipoles menghasilkan permukaan restorasi yang halus, licin dan mengkilap sehingga mengurangi porositas dan kandungan zat pada obat kumur chlorhexidine gluconate $0,2 \%$ yang terabsorpsi kedalam resin komposit lebih sedikit. Sesuai dengan pendapat Ningsih dan Indriani (2010), yang menyatakan bahwa restorasi yang dipoles dengan baik maka akan menunjukan hasil yang baik dibandingkan dengan permukaan restorasi yang kasar.

Penelitian ini menunjukan bahwa faktor ekstrinsik yaitu finishing dan polishing sangat berpengaruh untuk stabilitas warna dan ketahanan jangka panjang restorasi. Permukaan yang kasar dapat meningkatkan akumulasi plak, perubahan warna, karies sekunder dan memperburuk estetik serta kecerahan dari restorasi.. Polishing merupakan suatu prosedur pengubahan permukaan bahan restorasi yang kasar 
menjadi halus dan mengkilap. Polishing dapat dilakukan untuk mengurangi terjadinya diskolorisasi (perubahan warna) pada restorasi resin komposit. Restorasi yang tidak dipoles akan menghasilkan permukaan restorasi yang kasar sehingga menimbulkan stain pada permukaan restorasi Polishing dapat meningkatan kekuatan mekanik restorasi sehingga dapat memperpanjang masa pemakaian restorasi resin komposit serta meningkatkan sifat estetik restorasi resin komposit.

Meskipun kualitas restorasi resin komposit telah dikembangkan dengan teknologi baru pada beberapa tahun terakhir, perubahan warna tetap menjadi masalah utama. Perubahan warna yang signifikan dapat terjadi saat bahan restorasi terpapar zat pewarna makanan serta zat pewarna kimia. ${ }^{10}$ Seperti halnya yang terjadi pada sampel penelitian ini, pada sampel resin komposit nanofiller yang dipoles dan tidak dipoles memiliki perubahan warna karena direndam pada larutan obat kumur chlorhexidine gluconate 0,2\% dan aquades selama 5 hari. Pada sampel yang tidak dipoles memiliki perubahan warna yang lebih tinggi daripada sampel yang dipoles. Hal ini terjadi karena prosedur finishing dan polishing dapat mempengaruhi kehalusan permukaan resin komposit dan merupakan cara yang efektif untuk mengurangi perubahan warna (Martins A.L.B 2014).

Selain karena prosedur finishing dan polishing, perubahan warna yang terjadi pada resin komposit berkaitan dengan sifat penyerapan air yang dimiliki oleh resin komposit. Resin komposit memiliki kemampuan menyerap air sehingga larutan lain yang ada di rongga mulut dapat menyebabkan diskolorisasi. Air akan meresap ke dalam material resin komposit, kemudian mendegradasi ikatan siloxane melalui reaksi hidrolisis dan melemahkan ikatan bahan pengisi pada interfase matriks resin. ${ }^{12}$. Hal ini akan mengakibatkan air lebih mudah masuk ke dalam resin komposit sehingga dapat menyebabkan terjadinya perubahan warna.

Faktor ekstrinsik lain yang mempengaruhi perubahan warna adalah oral hygiene yang buruk, absopsi bahan pewarna seperti teh, minuman yang mengandung pigmen warna, kebiasaan merokok dan penggunaan obat kumur. Perubahan warna pada penelitian ini absorbsi dari obat kumur chlorhexidine gluconate 0,2\%. Penggunaan obat kumur chlorhexidine gluconate 0,2\% diketahui memiliki efek pewarnaan berupa noda berwarna kuning dan coklat pada rongga mulut misalnya gigi, mukosa dorsum lidah dan pada restorasi. Selain itu efek yang dapat ditimbulkan pada penggunaan obat kumur chlorhexidine gluconate 0,2\% dapat menyebabkan terjadinya gangguan pengecapan, serta peningkatan pembentukan kalkulus.

Chlorhexidine gluconate $0,2 \%$ merupakan merupakan bahan yang tidak berwarna yang melekat pada gigi dan akan menyebabkan pewarnaan resin komposit. Perubahan warna dalam perendaman resin komposit pada obat kumur dapat dipengaruhi oleh zat pewarna yang terkandung di dalamnya. Obat kumur yang digunakan dalam penelitian ini berwarna bening mengandung zat warna yaitu PEG-40 hydrogenated castor oil.

Zat warna tersebut yang menyebabkan dapat menempel pada permukaan resin komposit. Faktor lain yang dapat mempengaruhi perubahan warna yaitu presentase zat aktif chlorhexidine gluconate dalam obat kumur dapat menyebabkan resin komposit menjadi lebih translucent. Presentase chlorhexidine gluconate pada penelitian ini sebesar $0,2 \%$ yang mempunyai presentase yang tinggi sehingga kemungkinan dapat menyebabkan perubahan warna resin komposit. Obat kumur chlorhexidine gluconate 0,2\% akan meresap ke dalam bahan resin komposit, kemudian mendegradasi ikatan siloxane melalui reaksi hidrolisis dan mulai melemahkan ikatan bahan pengisi pada interfase matriks resin sehingga mengakibatkan air lebih mudah masuk ke dalam resin yang menyebabkan terjadinya perubahan warna.

Faktor intrinsik yang mempengaruhi perubahan warna resin komposit yaitu karakteristik bahan restorasi seperti jenis matriks organik, bahan pengisi dan komposisinya. Selain dari berbagai faktor tersebut, matriks resin merupakan faktor lain yang dapat menyebabkan terjadinya perubahan warna.

Komposisi matriks pada setiap resin komposit memiliki ukuran yang berbeda. Komposisi matriks yang berbeda dari resin komposit dapat mempengaruhi perubahan warna. Semakin banyaknya partikel yang terurai, maka semakin banyak pula cairan yang mampu masuk ke dalam matriks tersebut. Interfase matriks dengan bahan pengisi juga mempengaruhi jumlah absorpsi air ke dalam resin komposit yang berdampak pada stabilitas warna. Resin komposit konvensional atau macrofiller memiliki ukuran partikel bahan pengisi relatif besar dengan ukuran partikelnya $5-25 \mu \mathrm{m}$. Resin komposit mikfrofiller memiliki ukuran partikel 0,04$0,1 \mu \mathrm{m}$. Untuk resin komposit hybrid memiliki ukuran partikel 0,6 - 1 $\mu \mathrm{m}$. Sedangkan pada resin komposit nanofiller memiliki ukuran partikel bahan pengisi yang sangat kecil daripada resin komposit macrofiller, microfiller, dan resin komposit hybrid yaitu 0,005 $0,001 \mu \mathrm{m}$. Kandungan bahan pengisi pada resin komposit yang lebih rendah mampu menyerap air lebih banyak dibandingkan dengan resin komposit yang memiliki kandungan bahan pengisi lebih tinggi.

Berdasarkan penelitian ini, kandungan bahan pengisi pada resin komposit nanofiller adalah 78,5\% berat. Sedangkan untuk resin komposit macrofiller adalah 75 - $80 \%$ berat. Kandungan bahan pengisi pada resin komposit hybrid adalah $75-80 \%$ berat. Partikel bahan pengisi yang ditambahkan ke dalam matriks resin berfungsi untuk meningkatkan sifatnya, seperti sifat mekanis, antara lain kekerasa, kekuatan, absorpsi air serta berkurangnya pengkerutan karena jumlah resin. Oleh karena itu, semakin banyak jumlah kandungan bahan pengisi dan semakin kecil ukuran partikel fillernya maka semakin rapat kekuatan antar partikel sehingga menyebabkan perubahan warna lebih kecil.

Resin komposit nanofiller pada penelitian ini memiliki kandungan TEGMA yang lebih sedikit dan 
sebagai gantinya dilakukan penambahan UDMA yang menyebabkan resin komposit naofiller lebih mudah diaplikasikan dan penyerapan air jauh lebih sedikit dibanding resin komposit jenis lainnya. penambahan sedikit kandungan TEGMA pada Bis-GMA pada resin komposit dapat meningkatkan penyerapan air pada resin komposit, disebabkan oleh cairan yang dikonsumsi, sehingga menyebabkan resin komposit lebih rentan mengalami perubahan warna.

Pada penelitian ini, resin komposit nanofiller menyerap zat pewarna yang terkandung dalam obat kumur chlorhexidine gluconate $0,2 \%$, yaitu PEG-40 hydrogenated castor oil ke dalam matriks resin sehingga menyebabkan terjadinya perubahan warna pada permukaan resin komposit nanofiller.

\section{SIMPULAN}

Berdasarkan hasil penelitian yang telah dilakukan dapat disimpulkan bahwa terdapat perbedaan yang signifikan antara perubahan warna (diskolorisasi) resin komposit nanofiller yang dipoles dengan resin komposit nanofiller yang tidak dipoles pada perendaman dengan menggunakan larutan obat kumur chlorhexidine gluconate 0,2\%. Diskolorisasi lebih banyak terjadi pada restorasi resin komposit nanofiller yang tidak dipoles dibandingkan dengan restorasi resin komposit nanofiller yang dipoles.

\section{DAFTAR PUSTAKA}

1. Aprilia, Rochyani, Rahardianto, 2007.'Pengaruh Minuman Kopi Terhadap Perubahan Warna Pada Resin Komposit', Journal of Dentistry Indonesia, Universitas Indonesia, Jakarta, vol 14, no 3, pp. 164-170.

2. Ariana, Wibisono, Praptiningsih, 2015. 'Pengaruh Perasan Buah Lemon Terhadap Perubahan Peningkatan Warna Gigi', Medali Jurnal, Universitas Islam Sultan Agung, Universitas Diponegoro Semarang, vol 2 (1), 74-78.

3. Budirahardjo, 2011.'Pemutihan Kembali Gigi yang Berubah Warna Pada Anak', Journal of Dentomaxillofacial Science, Universitas Jember, Jember, vol 10, no 2, 105-110.

4. Fauziah, Fitriyani, Diansari. 2013, 'Colour Change of Enamel After Application of Averrhoa Bilimbi', Journal of Dentistry Indonesia, vol 19, no 3, 53-56.
5. Gogna, Jagadis, Shashikal, 2011.'A Comparative In Vitro Study of Microleakage By a Radioactive Isotope and Compressive Strength of Three Nanofilled Composite Resin Restorations', Journal of Conservative Dentistry, vol 14 (2), April-Juni, 128-131.

6. Majidah, Fatmawati, Gunadi. 2014,'Daya Antibakteri Ekstrak Daun Seledri (Apium Graveolens L) Terhadap Pertumbuhan Streptococcus Mutans Sebagai Alternatif Obat Kumur', Artikel Ilmiah Hasil Penelitian Mahasiswa, Universitas Jember, Jember.

7. Mervayano, Rahmatini, Bahar. 2015,'Perbandingan Efektivitas Obat Kumur yang Mengandung Chlorhexidine Dengan Povidone Iodine Terhadap Streptococcus', Jurnal Kesehatan Andalas, Universitas Andalas, Padang, vol 4, no 1.

8. Putriyanti, Herda, Soufyan. 2012,'Pengaruh Saliva Buatan Terhadap Diametral Tensile Strength Microfine Hybrid Resin Composite yang Direndam Dalam Isotonic', Jurnal PDGI, Universitas Indonesia, Jakarta, vol 61, no 1, Januari-April, 43-47.

9. Rochmah, Dwi Merry Ch.R, Lestari. 2014,'Potensi Jeruk Nipis (Citrus Aurantifolia) Dalam Memutihkan Email Gigi yang Mengalami Diskolorisasi', IDJ, Universitas Jember, Jember, vol 3, no 1.

10. Rusmayati, Erlita, M., Yanuar, Ichrom Nahzi. 2017,'Perbedaan Perubahan Warna Resin Komposit Nanofiller yang Dipoles dan Tidak Dipoles Pada Perendaman Larutan Teh Hijau', Journal of Dentistry Indonesia, Universitas Lambung Mangkurat, Banjarmasin, vol 2, no 1.

11. Thambas A, Sari Dewi, 2012.'Pengembangan dan Modifikasi Estetik Dalam Pembuatan Crown Bridge', Journal Ilmiah, Universitas Prof. Dr. Moestopo, Universitas Indonesia, Juli-Agustus.

12. Widyastuti, Hermanegara. 2017,'Perbedaan Perubahan Warna Antara Resin Komposit Konvensial, Hybrid dan Nanofill Setelah Direndam Dalam Obat Kumur Chlorhexidine Gluconate 0,2\%, Jurnal Ilmu Kedokteran Gigi, Universitas Muhhamadiyah, Surakarta, vol 1, no 1 
